\title{
Determining the environmental situation as a factor in the differentiation of housing prices in Nur-Sultan by using the Analytic Hierarchy Process
}

\author{
Kamila Akhmedinova* \\ Peoples' Friendship University of Russia (RUDN University), Faculty of Ecology, 6 Miklukho- \\ Maklaya St, Moscow, 117198, Russian Federation
}

\begin{abstract}
Modern cities, being centers of intellectual activity, trade, culture, science and development, are becoming places of attraction for people. It is in urban conditions that the economic and social evolution of man takes place. At the same time, as urbanization grows, a number of problems arise, including environmental ones. Therefore, it is necessary to take environmental factors into account when planning urban development, housing construction and creating infrastructure. This study is devoted to the application of the method of hierarchy of stochastic systems using the technology of geographic information systems, allowing to assess the adequacy of the cost of housing in relation to the environmental situation in the city of Nur-Sultan.
\end{abstract}

\section{Introduction}

Environmental problems in the modern world are becoming widespread, thereby emphasizing relevance now. The ecological situation, especially in large urban agglomerations, is dangerous for the townspeople due to non-compliance with environmental standards. Consequently, the priority policy direction is the efficient use of land resources and the corresponding consideration of environmental factors in determining the prices of real estate [1]. The environmental factors in the context of this work are natural and natural-anthropogenic factors that are not means of labor, commodities or sources of energy and raw materials, but that directly affect the efficiency and usefulness of using the property.

Thus, the environmental factor becomes the most important factor in the pricing of real estate and takes on a new meaning in a new post-industrial society. Modern trends, in this context, serve as an additional indicator for determining the development of society, since environmental education is an integral part of a new stage of development [2].

\footnotetext{
*Corresponding author: akhmedinovakamila@gmail.com
} 


\section{Methods}

The aim of the work is to study the relationship between environmental load and property value. For this, the Pearson Correlation Criterion will be used.

The main tasks set to achieve the goal:

- Differentiation of habitats obtained using the Analytic Hierarchy Process

- Identification of the main types of pollution of environmental components.

The AHP method allows to structure and understand in a clear and rational way a complex decision-making problem in the form of a hierarchy, to compare and quantify alternative solutions. In our particular case, compare the areas of the city by environmental characteristics. AHP application procedure:

- Construction of a qualitative model of the problem in the form of a hierarchy that includes a goal, alternative options for achieving the goal and criteria for assessing the quality of alternatives.

- Prioritization of all elements of the hierarchy using the method of pairwise comparisons.

- Synthesis of global priorities of alternatives by linearly folding the priorities of the elements in the hierarchy.

- Verification of judgments for consistency.

- Making decisions based on the results obtained.

Table 1. Initial value of factors.

\begin{tabular}{|c|c|c|c|c|c|c|c|}
\hline & $\begin{array}{c}\text { Stationary } \\
\text { sources of } \\
\text { pollution, } \\
\mathrm{t} / \text { year }\end{array}$ & $\begin{array}{c}\text { Mobile } \\
\text { sources of } \\
\text { pollution, } \\
\mathrm{t} / \text { year }\end{array}$ & $\begin{array}{c}\text { Hydrospher } \\
\text { e Pollution / } \\
\text { MPC }\end{array}$ & $\begin{array}{c}\text { Soil } \\
\text { pollutio } \\
\mathrm{n}, \\
\text { Kc }\end{array}$ & $\begin{array}{c}\text { Radiation } \\
\text { pollution,S } \\
\mathrm{V}\end{array}$ & $\begin{array}{c}\text { Noise } \\
\text { pollution, } \\
\mathrm{dB}\end{array}$ & $\begin{array}{c}\text { Mechanical } \\
\text { pollution, S }\end{array}$ \\
\hline Area 1 & $\mathrm{x}$ & $\mathrm{x}$ & $\mathrm{x}$ & $\mathrm{x}$ & $\mathrm{x}$ & $\mathrm{x}$ & $\mathrm{x}$ \\
\hline$\ldots . . . .$. & $\ldots$ & $\ldots$ & $\ldots$ & $\ldots$ & $\ldots$ & $\ldots$ & $\ldots$ \\
\hline Area N & $\mathrm{N}$ & $\mathrm{N}$ & $\mathrm{N}$ & $\mathrm{N}$ & $\mathrm{N}$ & $\mathrm{N}$ & $\mathrm{N}$ \\
\hline
\end{tabular}

Having determined the main goal, we proceed to a pairwise comparison of environmental factors. It is also important to accept the following ratios of dominant factors $[3,4]$.

The radiation factor has $(\mathrm{RP})$ :

- absolute preference over soil contamination factor;

- obvious preference over mechanical contamination;

- a preference, a compromise between the essential and the obvious, over the noise pollution factor;

- significant preference over the hydrosphere pollution factor;

- preference, a compromise between insignificant and substantial, over the stationary pollution factor;

- a preference, a compromise between insignificant and substantial, over the factor of mobile pollution.

The stationary source factor has (SSP):

- absolute preference over soil contamination factor;

- obvious preference over mechanical contamination;

- preference, a compromise between the insignificant and the obvious, over the factor of mobile sources of pollution;

- a preference, a compromise between the essential and the obvious, over the pollution factor of the hydrosphere; 
- obvious preference over noise pollution;

The factor of mobile sources of pollution has (MSP):

- a preference, a compromise between the essential and the obvious, over the pollution factor of the hydrosphere;

- absolute preference over soil contamination factor;

- obvious preference over noise pollution;

- obvious preference over mechanical contamination.

The hydrosphere pollution factor has (HP):

- obvious preference over noise pollution;

- slight preference over soil contamination;

- preference, a compromise between the essential and the obvious, over the factor of mechanical pollution.

The noise pollution factor has (NP):

- obvious preference over soil contamination;

- preference, a compromise between the essential and the obvious, over the factor of mechanical pollution.

The mechanical pollution factor has (MP):

- obvious preference over soil contamination (SP)

Based on the above, we can compare the weight of factors:

Table 2. The weight of factors.

\begin{tabular}{|c|c|c|c|c|c|c|c|c|c|c|}
\hline Factors & SSP & MSP & HP & SP & RP & MP & NP & Op & Exp (1/9) & Value \\
\hline SSP & 1 & 2 & 3 & 7 & 0.5 & 0.5 & 6 & 63 & 1.8069 & 0.2082 \\
\hline MSP & 0.5 & 1 & 3 & 6 & 0.5 & 2 & 6 & 54 & 1.7676 & 0.2037 \\
\hline HP & 0.3333 & 0.3333 & 1 & 2 & 0.2 & 2 & 3 & 0.2663 & 0.8278 & 0.0954 \\
\hline SP & 0.1428 & 0.1665 & 0.5 & 1 & 0.1428 & 0.3333 & 0.5 & 0.0002 & 0.2963 & 0.0342 \\
\hline RP & 2 & 2 & 5 & 7 & 1 & 5 & 5 & 1400 & 2.8136 & 0.3243 \\
\hline MP & 2 & 0.5 & 0.5 & 3 & 0.2 & 1 & 2 & 0.6 & 0.7573 & 0.0874 \\
\hline NP & 0.1666 & 0.166 & 0.333 & 2 & 0.2 & 0.5 & 1 & 0.0018 & 0.4055 & 0.0467 \\
\hline & 6.1427 & 6.1665 & 13.3333 & 28 & 2.7428 & 11.3333 & 23.5 & & 8.675 & 1 \\
\hline
\end{tabular}

\section{Results and discussions}

After a pairwise evaluation of factors, the product of the values of their evaluation is calculated in rows, and then the root of the degree to which the number of factors is estimated is extracted from the obtained value. The weight of the factor is determined by dividing the value obtained by extracting the root by the sum of these valuesfor all factors. As a result, the sum of the weight of all factors must be equal to unity [5].

To control the accuracy of factor comparisons, the Consistency Indicator (CI) is calculated as the sum of the products of the sum of the values of the factor assessment in the row and column for each factor. Then, the consistency index (CIndex) is calculated as the quotient of dividing the difference between the $\mathrm{CI}$ and the number of factors by the difference in the number of factors and units.

Next, the consistency ratio (CR) is calculated as the quotient of dividing the Cndex by a random index (RI). CR should be less than 0.1 ; otherwise, it is necessary to check the 
correctness of the assessment of factors. RI depends on the number of factors and is selected from table 3 .

Table 3. Random Index Values.

\begin{tabular}{|c|c|c|c|c|c|c|c|c|c|c|}
\hline $\begin{array}{c}\text { Number of } \\
\text { factors }\end{array}$ & 1 & 2 & 3 & 4 & 5 & 6 & 7 & 8 & 9 & 10 \\
\hline Random index & 0 & 0 & 0.58 & 0.9 & 1.12 & 1.24 & 1.32 & 1.41 & 1.45 & 1.49 \\
\hline
\end{tabular}

Since the CR obtained is $<0.1$, the estimates do not have significant contradictions and can be taken for further calculations [6].

In order to make a final decision on the choice, it is necessary to transfer the value of priority vectors from all tables for each factor to the final table and calculate the global priority. It is defined as the sum of the products of the factor weighting by the criterion priority factor.

Based on the above methodology and taking into account all factors, the following map was compiled for all factors, both intermediate and informative (Fig. 1).

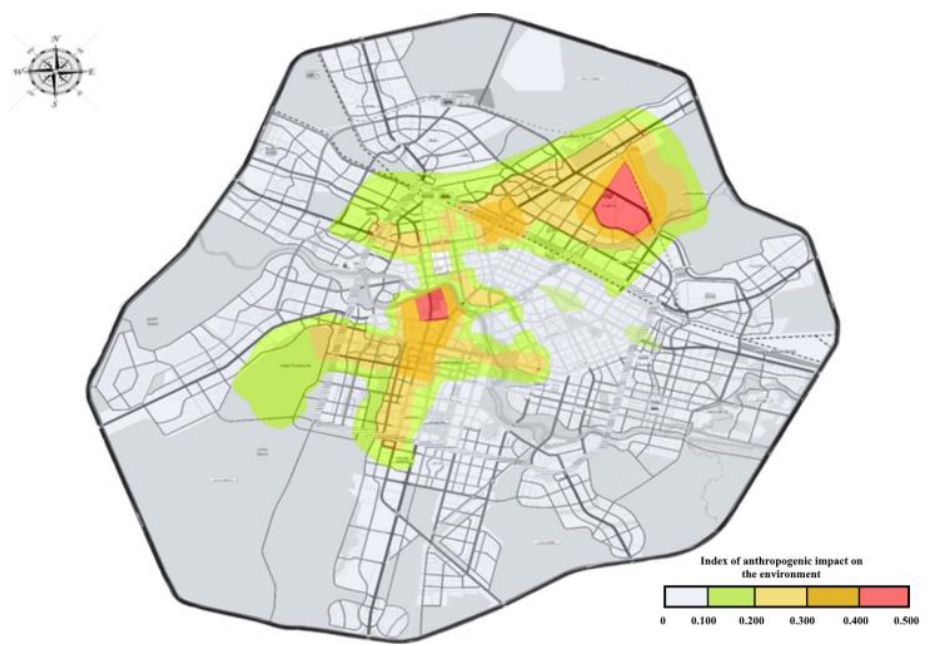

Fig. 1. Index of ecological load on natural environmental components in Nur-Sultan (according [7, 8, $9,10,11])$.

As a result, taking into account all factors, we obtain the full environmental load in the city of Nur - Sultan. The map was overlaid with a map of the cost per square meter, which we received using open sources (Krysha.kz).

For representativeness of the analysis, we used the BCG diagram of B. Henderson [12]. The data are presented in the fig. 2 [13].

Results were highlighted in 5 categories:

- 1 category - groups C-I, D-1, D-II. This category includes a high pollution index and low property value. Only 2 districts of the city fall into category 1 , which is $4.2 \%$.

- 2 category - groups D-III, D-IV, C-IV. This category includes a high pollution index and the highest value of real estate. In the 2 nd category, only 1 district

- 3 category - groups B-IV, A-IV, A-III. This category is characterized by the minimum values of the pollution index and the highest cost per square meter. 3 microdistricts of the city belong to the 3 category, $6.25 \%$ - Med.gorod,Astana Arena, and EXPO. 
- 4th category - groups A-I, A-II, B-I. This category is characterized by the lowest values of the pollution index and the lowest cost per square meter. This category includes 16 microdistricts of the city, which is $33.3 \%$.

-5 category - groups B-II, C-II, C-III, C-IV. This category is characterized by average pollution index and cost per square meter. This category includes 26 microdistricts or $54.2 \%$. This is the main category [14].

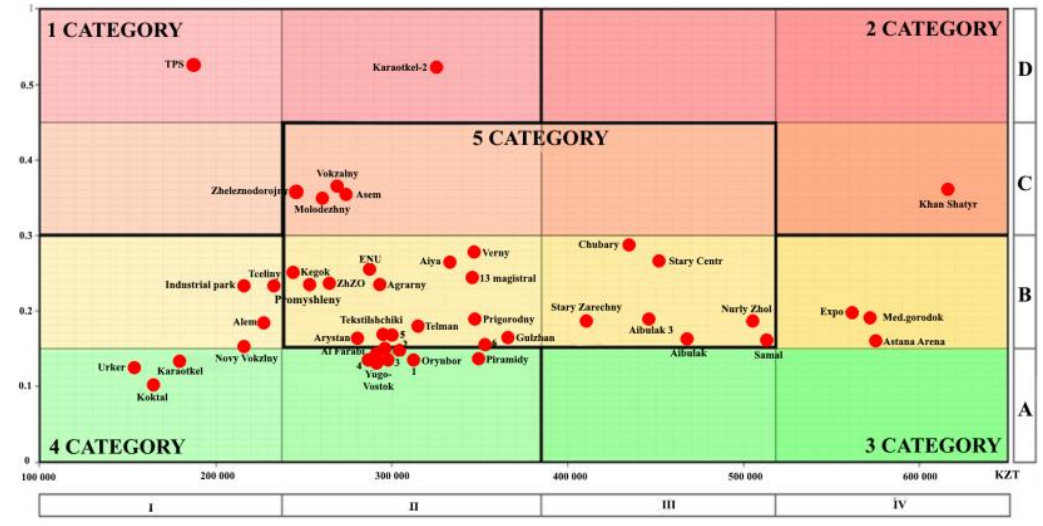

Fig. 2. A diagram of the relationship between the pollution index and the average cost per square meter in different microdistricts of Nur-Sultan.

The use of the Analytic Hierarchy Process allowed us to conclude the following. Only $10.4 \%$ of cases the state of the environment was adequate to the environmental situation, and high real estate prices coincided with the optimal ecological characteristics of the area [15].

\section{Conclusions}

It can be concluded that at present the environmental situation plays a weak role in the pricing of Nur-Sultan real estate market, while prestige is an important factor. It should also be noted that the impact of the environmental factor is often limited to "visible" environmental problems rather than "invisible" ones. Therefore, for example, the contribution of radiation exposure is levelled out and, on the contrary, the perception of industrial enterprises, thermal power plants, etc. is aggravated.

The city of Nur-Sultan is positioning as a city of the future, but a necessary condition for achieving this result is the creation of a safe and secure environmental situation. For this, some recommendations for solving the main environmental problems in the city can be offered.

- Tightening the legal framework in the field of environmental protection is necessary, as well as the stable development of public authorities in the field of environmental safety.

- The condition of "invisible" factors, such as the radiation environment, should be monitored and the results made available to the public.

- The transition to more environmentally friendly vehicles can help to resolve a problem of emission. However, the low standard of living of the population will not allow this in the near future.

- It is necessary to increase in density of green spaces, primary along the roads.

The influence of the environmental factor is often limited by the action of "visible" environmental problems than "invisible" ones. Therefore, the contribution of radiation 
exposure is leveled and, on the contrary, the perception of industrial enterprises, thermal power plants, etc. is sharpened.

\section{References}

1. D. L. Volkov, Real Estate Economics and Finance, 32 (SPbGU, St. Petersburg, 1999) (in Russian)

2. A.V. Sevost'yanov, Economic valuation of real estate and investments (Akademiya, Moscow, 2008) (in Russian)

3. M. Kac and J. Logan, In Fluctuation Phenomena, eds. E.W. Montroll \& J.L. Lebowitz (North-Holland Publ.Co, Amsterdam, 1979)

4. E. Nelson, Quantum Fluctuations (Princeton University Press, Princeton, 1985)

5. Wei G.W, Planck equation. J. Phys. A: Mathematical and General, 33, 4935- 4953 (2000)

6. M.E. Shaikin. J. Automation and Remote Control, 63:5, 766-776 (2002)

7. The newsletter on the state of the environment of the Republic of Kazakhstan for 2018 Available at: https://kazhydromet.kz/ecology/informacionnye-byulleteni-o-sostoyaniiokruzhayuschey-sredy-respubliki-kazahstan

8. The newsletter on the state of the environment of the Republic of Kazakhstan for 2019 Available at: https://kazhydromet.kz/ecology/informacionnye-byulleteni-o-sostoyaniiokruzhayuschey-sredy-respubliki-kazahstan

9. J.N. Zaturanov, T.N. Antipova, Scient.J. NRU ITMO, 1, 15 (2013)

10. Ko Wang, Marvin L. Wolverton Real Estate Valuation Theory (Springer US. Kluwer Academic Publishers, 2002)

11. N.I Ivanov, M.V. Butorina, N.N. Minina, Vestnik MGSU 3-1 (2011)

12. B. Bultena, B. Grünbaum and F. Ruskey, J., Comp.sciense, Math. CCCG (1999)

13. N. J. A. Sloane and S. Plouffe, The Encyclopedia of Integer Sequences (Academic Press, New York, 1995)

14. D. Hubbard How to Measure Anything: Finding the Value of Intangibles in Business pg. 46 (John Wiley \& Sons, 2007)

15. P. Silaeva, K. Akhmedinova, M. Redina, A. Khaustov. $18^{\text {th }}$ International Multidisciplinary Scientific GeoConference SGEM2018, 18, 727-732 (2018) 